\title{
TEPHROSIA WOODII (LEGUMINOSAE), UNA NUEVA ESPECIE DEL ESTADO DE OAXACA, MEXICO.
}

\author{
Oswaldo Téllez Valdéz*
}

Como parte del proyecto "Las Leguminosas del Estado de Oaxaca" se está elaborando la revisión del género Tephrosia, la cual a aportado una nueva especie para la ciencia.

Como reconocimiento a su labor en este género se le dedica esta especie al Dr. Carroll E. Wood, Jr. de la Universidad de Harvard.

\section{Tephrosia woodii Téllez sp. nov.}

Planta perennis erecta herbacea vel suffruticosa 0.5-2.0 m alta. Caules subflexuosi, | hirtelli vel strigillosi pilis fulvis. Folia (8-) $13-25 \mathrm{~cm}$ longa, petiolis $5-15 \mathrm{~mm}$ longis; stipulae lineari-lanceolatae 6-7 mm longae, deciduae; foliola 11-23, superiora lanceolata, apice acuto, mucronato, basi rotundata, (30-) 60-100 mm longa, (11-) 15-21 (-29) mm lata, terminale maximum; inferiora minima, elliptica vel ovato-lanceolata, $26-65 \mathrm{~mm}$ longa, 7-21 mm lata; foliola tenua, venis conspicuis supra leviter nitida glabrata vel strigillosa subtus pallidiora, dense strigillosa pilis cinereis.

Inflorescentiae terminales et axillares, (4-) $12-16 \mathrm{~cm}$ longae, graciles laxae ascendentes, pedunculis (6-) 21-38 mm longis; nodi floriferi (7-1) 12-25; alabastris 3-5 per nodum. Bracteae lineari-subulatae, angustatae, $6-8 \mathrm{~mm}$ longae, persistentes; bracteae secundariae 5-8 mm longae, persistentes. Pedicelli 5-7 mm longi, graciles, hirtelli vel hirsutuli pilis cinereis. Calyx 5-6 mm longus, strigillosus vel breviter strigosus pilis cinereis; lobi vexillares setacei 1.2 mm longi; lobi laterales deltoidei vel ovato - deltoidei 2.5-3 mm longi; lobus carinalis deltoideus vel ovatus $3.5 .5 \mathrm{~mm}$ longus. Corolla roseo-lilacina.

Vexilli basis macula viridi, lamina suborbicularis, $11.12 \mathrm{~mm}$ longa, 12.13 $\mathrm{mm}$ lata extus strigillosa pilis furrugineis; alae $10-11 \mathrm{~mm}$ longae, $5.6 \mathrm{~mm}$ lata, ungue $4 \mathrm{~mm}$ longa. Tubus staminalis 10-11 mm longus; stamina pseudomonadelpha, estamen vexillare tubo connatum, basi liberum. Ovarium dense breviter strigosum. Legumen 3-4 cm longum, 5-6 $\mathrm{mm}$ latum, hirsutulum pilis cinereis, semina 5 . vel $7,3-4 \mathrm{~mm}$ longa $2.5 \mathrm{~mm}$ lata.

Planta perenne erecta, herbacea a sufruticosa, de $0.5-2.0 \mathrm{~m}$ de alto. Tallos subcilindricos angulados o surcado-estriados. Hojas de (8-) $13.25 \mathrm{~cm}$ de largo, pecíolos de 5-15 mm de largo; estípulas lineal-lanceoladas, acuminadas de 6-7 mm de largo

* Jardín Botánico, Instituto de Biología U.N.A.M.

Téllez-Valdéz O. 1979. Tephrosia woodii (Leguminosae), una nueva especie del estado de Oaxaca, México. Boletín de la Sociedad Botánica de México 38: 77-82. 
usualmente deciudas; folíolos 11-23, ovado-lanceolados a oblongo-lanceolados, ápice agudo, mucronado, base redondeada, de (30-) 60-100 mm de largo y (11-) 15-21 (-29) $\mathrm{mm}$ de ancho, folíolos inferiores pequeños, elípticos a ovado-lanceolados, $26-65 \mathrm{~mm}$ de largo 7-21 mm de ancho, delgados, con venación conspicua, haz glabro a moderadamente estriguloso a corto estrigoso con pelos cinéreos; pecíolulos 1.5-2.0 mm de largo. Inflorescencias terminales y axilares, 1 a 3 ramas por axila, inflorescencias en pseudorracimos, las flores en grupos o fasciculos; inflorescencias de (4-) $12-16 \mathrm{~cm}$ de largo, pedúnculos (6-) 21-38 mm de largo, nodulos florales (7-) 12-25, brotes 3.5 por nódulo. Brácteas lineal-subuladas, estrechas, de $6.8 \mathrm{~mm}$ de largo, persistentes; brácteas secundarias 5.8 mm de largo, persistentes, bracteolas ausentes. Pedicelos 5-7 mun de largo, Cáliz y pedicelos hirsútulos con pelos cinéreos a pardo claros; cáliz $5.6 \mathrm{~mm}$ de largo, lóbulo vexilar setáceo de $1.2 \mathrm{~mm}$ de largo, lóbulos laterales y carinal deltoides a deltoide-ovados de 2.5-3 $\mathrm{mm}$ y 3-3.5 mm de largo respectivamente. Flores rosado-lilas, vexilo con macula verde en la base; vexilo suborbicular, estriguloso con pelos pardo-rojizos en el dorso, lámina de 11-12 mm de largo, $12.13 \mathrm{~mm}$ de ancho, uña $3 \mathrm{~mm}$ de largo; alas, lámina 10-11 mm de largo, $4.5 \mathrm{~mm}$ de ancho, uña 3.4 mm de largo; carina, lámina 10-11 mm de largo, 5-6 mm de ancho, uña $4 \mathrm{~mm}$ de largo. Tubo estaminal 10-11 mm de largo, estambres pseudomonadelfos., estambre vexilar libre en la base. Ovario densamente estrigoso a hirsútulo, estilo barbado en el margen vexilar. Fruto maduro casi recto, $3-4 \mathrm{~cm}$ de largo, 5-6 mm de ancho, esparcidamente hirsútulo con pelos cinéreos, semillas de 5 a 7 casi cilíndricas u mblongas, pardo claras a grises, $3-4 \mathrm{~mm}$ de largo, $2.5 \mathrm{~mm}$ de ancho y $2 \mathrm{~mm}$ de grosor.

Epoca de floración: octubre a enero.

Distribución: México: Oaxaca; en bosques de Pinus, Pinus-Quercus y Quercus, en altitudes de 800-950 m, en la región de la Sierra Madre del Sur, șobre las sierras de San Pedro el Alto y Malinaltepec, en las zonas de San Gabriel Mixtepec y Putla de Guerrero, respectivamente (ver mapa).

TIPO: México: Oaxaca; a $5 \mathrm{~km}$ al NE de Putla de Guerrero, Distrito de Putla, altitud 850 m, bosque de Pinus; 6 XII 78; M. Sousa 9885 y S. Zarate (HOLOTIPO-MEXU).

Material adicional: Oaxaca; A 5-6 km al NE de Putla de Guerrero; 6 II 65: $R$. McVaugh 22259 (ENCB). A $4 \mathrm{~km}$ al NE de Putla de Guerrero; 16 IV 76; M. Sousa 54 78, 0. Téllez y A.S. Magallanes (MEXU). A $7 \mathrm{~km}$ al NE de Putla de Guerrero; 3 II 77; Sousa 7010 Téllez, M. Ladd y J.C. Soto (MEXU). A 2 km al NE de Putla de Guerrero; 3 II 77; Sousa 7020 Téllez; Ladd y Soto (MEXU). A 8 km al S de Putla de Guerrero; 3 II 77; Sousa 7023, Téllez, Ladd y Soto (MEXU). A $13 \mathrm{~km}$ al NE de San Gabriel Mixtepec, Distrito de Juquila; 10 II 77; Sousa 7168, Téllez, Ladd y Soto (MEXU). 


\section{CLAVE PARA SEPARAR LA ESPECIE CONSIDERADA DE LAS ESPECIES AFINES}

A. Cáliz de 8-10 $\mathrm{mm}$ de largo

B. estípulas y brácteas de 6-8 $\mathrm{mm}$ de largo, 0.5-1.0 $\mathrm{mm}$ de ancho ...T. simulans

BB. estípulas y brácteas de $12-15 \mathrm{~mm}$ de largo, 1.5-2.0 $\mathrm{mm}$ de ancho. T. langlassei

AA. Cáliz de 5-7 $\mathrm{mm}$ de largo

C. hojas sésiles, lóbulos del cáliz oblongos a obovados . . . . . . T. belizensis

CC. Hojas pecioladas, pecíolo de 5-20 mm de largo; lóbulos del cáliz déltoides a ovados

D. folíolos 7-13; pedúnculo de la inflorescencia $40-60 \mathrm{~mm}$ de largo; Tubo estaminal $12-14 \mathrm{~mm}$ de largo . . . . . . mexicana

DD. folíolos 11-23; pedúnculo de la inflorescencia (6-) $21-38 \mathrm{~mm}$ de largo; Tubo estaminal $10.11 \mathrm{~mm}$ de largo . . . . . . . . T. woodii

Esta especie y $T$. mexicana con la que se encuentra cercanamente relacionada, comparten una serie de características; la forma ovado-lanceolada a oblongo-lanceolada y la pubescencia estrigulosa a corto estrigosa de los folíolos, la presencia de pseudorracimos axilares y terminales, el mismo número de óvulos y semillas que es de 5 a 7 y la misma época de floración; pero a su vez, estas son claramente separadas como dos especies por las diferencias que se establecen en la tabla No. 1

\section{AGRADECIMIENTOS}

Se agradece al M. en C. Mario Sousa por su guía desde el trabajo de campo hasta la revisión del texto. Al Dr. Jerzy Rzedowski y al Biól. Fernando Chiang por su revisión y valiosas sugerencias asi como su aportación en la diagnosis latina. También sè agradece a los curadores del ENCB, GH, MEXY, NY, UC por facilitar su material ya sea en prestamo o en consulta directa, para el buen logro de este trabajo. 
TABLA No. 1

T. woodii

T. mexicana*

\begin{tabular}{|c|c|c|}
\hline Tamaño de las hojas & $8.25 \mathrm{~cm}$ & (4-) $6-11 \mathrm{~cm}$ \\
\hline Número de folíolos & .11 .23 & 7.13 \\
\hline $\begin{array}{l}\text { Tamaño del pedúnculo de la } \\
\text { inflorescencia }\end{array}$ & (6-) $21-38 \mathrm{~mm}$ & $40-60 \mathrm{~mm}$ \\
\hline $\begin{array}{l}\text { Tamaño de las inflorescen- } \\
\text { cias }\end{array}$ & (4.) $12.16 \mathrm{~cm}$ & $8-25 \mathrm{~cm}$ \\
\hline Forma de las inflorescencias & $\begin{array}{l}\text { pseudorracimos cortos seme- } \\
\text { jando paniculas }\end{array}$ & $\begin{array}{l}\text { pseudorracimos largos seme- } \\
\text { jando racimos simples }\end{array}$ \\
\hline $\begin{array}{l}\text { Forma y tamaño de los lóbu- } \\
\text { los del cáliz }\end{array}$ & $\begin{array}{l}\text { carinal y laterales deltoide- } \\
\text { ovados y deltoides de } 3-3.5 \text { y } \\
2.5-3 \mathrm{~mm} \text { de largo respecti- } \\
\text { vamente. }\end{array}$ & $\begin{array}{l}\text { carinal y laterales ovados } \\
\text { abruptamente acuminados } \\
\text { de } 3.5-4.5 \text { y } 3.5-4 \mathrm{~mm} \text { de } \\
\text { largo respectivamente. }\end{array}$ \\
\hline Tubo estaminal & $10-11 \mathrm{~mm}$ & $12-14 \mathrm{~mm}$ \\
\hline Tamaño de los pétalos & $\begin{array}{l}\text { alas } 10-11 \mathrm{~mm} \\
\text { carina } 10.11 \mathrm{~mm} .\end{array}$ & $\begin{array}{l}\text { alas } 14.16 \mathrm{~mm} \\
\text { carina } 15.16 \mathrm{~mm}\end{array}$ \\
\hline $\begin{array}{l}\text { Distribución y rango altitudi- } \\
\text { nal }\end{array}$ & $\begin{array}{l}\text { Estado de Oaxaca } \\
800-950 \mathrm{~m}\end{array}$ & $\begin{array}{l}\text { Estado de México } \\
2000 \mathrm{~m}\end{array}$ \\
\hline
\end{tabular}

* Material consultado: TIPO: México; Cumbre de Tejupilco, Distrito de Temascaltepee, G.B. Hinton 2698; 24 XI 1932. (GH-TIPO; NY,UC). A $2 \mathrm{Km}$ al S de Ocotepec, Mpio de Tejupilco, J. Rzedonshi 25275; 10 XII 1967. (ENCB). En Ámatepec. Distrito de Temascaltepec, E. Matuda 29845; 27 XII 1953 (MEXU).

\section{RESUMEN}

Se describe una especie nueva, Tephrosia woodii (Leguminosae) del Estado de Oaxaca, México, se da distribución geográfica y datos ecológicos, se discute brevemente su relación con $T$. mexicana y se elabora clave para su separación te las especies afines. 
TEPHROSIA WOODII NUEVA ESPECIE DE OAXACA

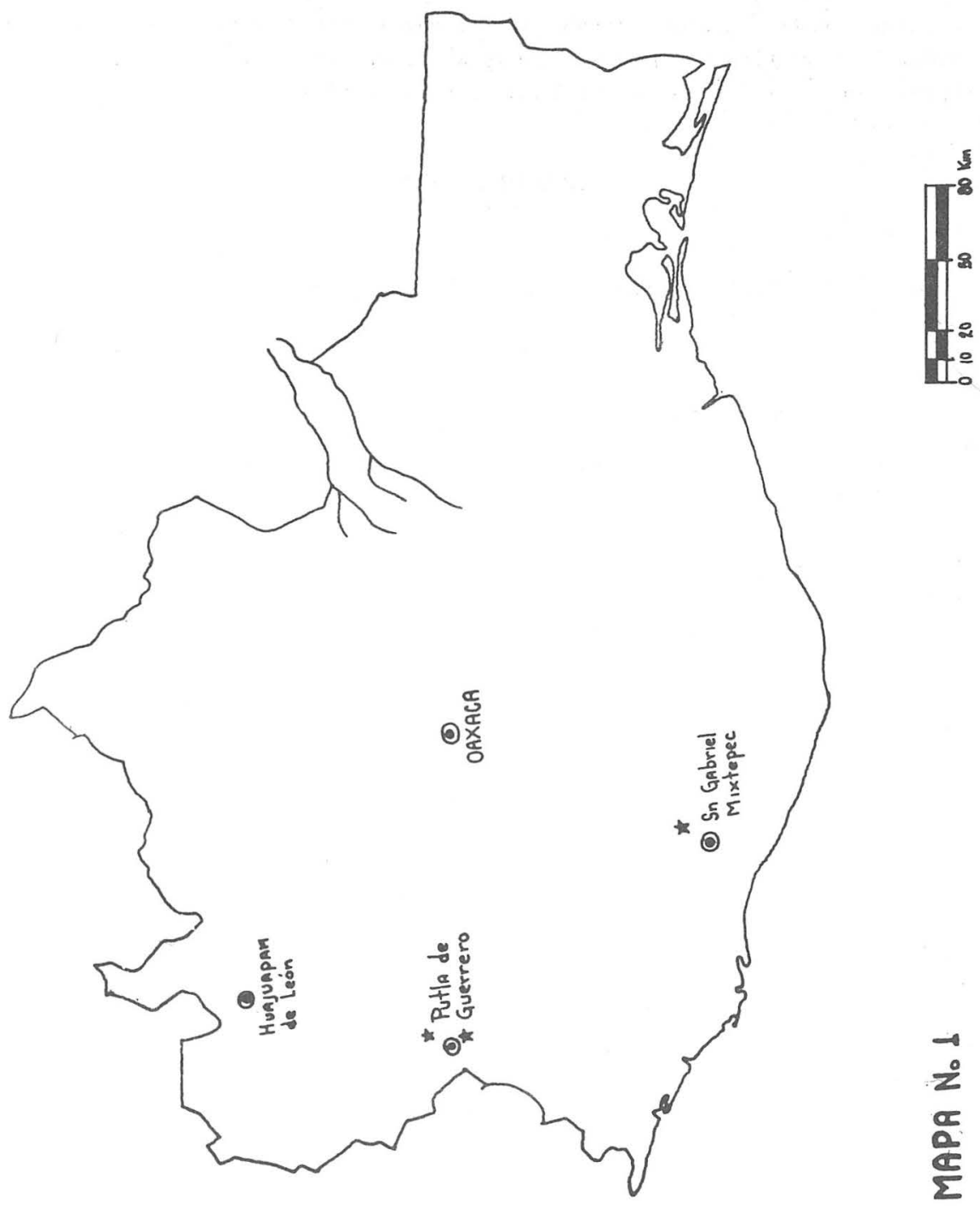




\section{SUMMARY}

A new species Tephrosia woodii (Leguminosae) from Oaxaca State, México is described, geographic distribution and ecological notes are given and its relationship with T. mexicana is briefly discussed; a systematic key is presented.

\section{BIBLIOGRAFIA}

Wood. C. E., 1949. The American barbistyled species of Tephrosia (Leguminosae). Rhodora 51 (170):193-384. 